\title{
WAS BLEIBT
}

\section{Liebe Leserin, lieber Leser,}

das Jahr neigt sich seinem Ende zu, Sie halten das letzte Heft von 2014 in den Händen. Schon wieder sind 52 Wochen vorbei, von allen guten Vorsätzen, die sicher viele letztes Silvester getroffen hatten, sind wieder nur wenige umgesetzt. Manche konnten tatsächlich mit dem Rauchen aufhören, andere realisierten den Vorsatz, weniger Gewicht auf die Waage $\mathrm{zu}$ heben. So hat vielleicht jeder sein kleines Erfolgserlebnis im privaten Bereich.

Doch was waren geschäftlich in der Automobilindustrie die Highlights des nun zur Neige gehenden Jahres 2014? Was wird bleiben, wenn man an 2014 zurückdenkt? Sicher ist die Elektromobilität in diesem Jahr einen großen Schritt vorangekommen. Auf den Hype folgte ein größerer Realitätssinn für das Machbare und Sinnvolle. So wurde 2014 zum Beispiel der erste BMW i3 ausgeliefert, ein für die Branche wegweisendes Gefährt. Betrüblicher ist da die 2014er-Meldung aus Rüsselsheim, dass die Produktion des Ampera 2016 eingestellt wird.

Aufregerthema Nr. 1 des Jahres war und ist noch der langwierige Kältemittelstreit um R134a, R1234yf und $\mathrm{CO}_{2}$, über den wir mit Fachartikeln und Reports sowie Online-Dossiers auf www.springerprofessional.de, aber auch in Editorials ausführlich berichteten und pointiert diskutierten. Letzte Online-Nachricht dazu ist, dass Brüssel im Streit um das Kältemittel R1234yf in Mercedes-Klimaanlagen den Druck auf Deutschland erhöht hat. Die Europäische Kommission leitete die nächste Stufe eines Verfahrens wegen Verletzung der EU-Verträge ein.

Als zweiter Dauerbrenner kann sicher die deutsche Pkw-Maut gelten. Kommt sie, kommt sie nicht? Da gibt es viele Fragen, die von Verkehrsminister Alexander Dobrindt bis heute nicht beantwortet wurden. Bereits im Juli hatte er sein Konzept vorgestellt. Nach viel Kritik bemängelte im September auch der IT-Branchenverband Bitkom das Konzept. Die geplante Umsetzung sei halbherzig - und die Technik hinter der Maut nicht auf dem neuesten Stand.

Und was war für uns in der Redaktion das Ereignis des Jahres? Sicher das 75. Jubiläum des Schwestermagazins, der MTZ Motortechnischen Zeitschrift. Aus Sicht der alten Dame ATZ im bald 117. Jahrgang ist die MTZ ja 41 Jahre frischer und somit noch ein junges Mädchen. Wir feierten das Jubiläum mit einer gelungenen Feier im Mahle Inside, wo viele Gäste, Freunde und wohlgesonnene Partner aus dem Bereich Antriebe und Motoren begrüßt wurden.

Das neue Jahr wird sicher genauso fortschrittlich wie das alte. Denn wie Wilhelm Busch sagte: Eins, zwei, drei, im Sauseschritt, eilt die Zeit - wir eilen mit. Lassen Sie sich im Januarheft vom ATZ-Relaunch überraschen.

Herzlichst, Ihr

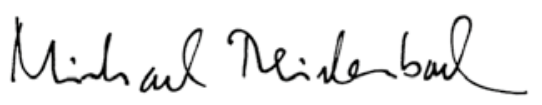

Dipl.-Ing. Michael Reichenbach,

Stellvertretender Chefredakteur Wiesbaden, den 27. Oktober 2014

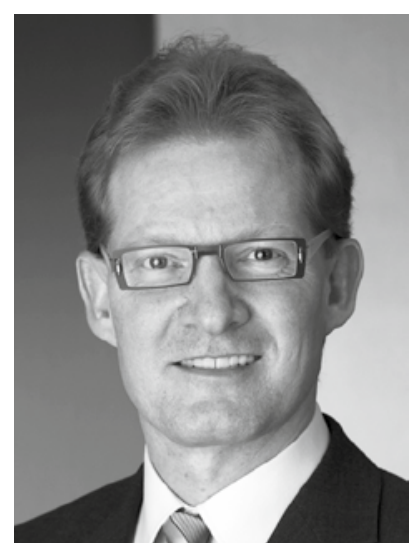

Wir

\section{entwickeln, was bewegt}

\section{IAV - Ihr Partner \\ für Automotive \\ Engineering}

